\title{
High Efficiency Double-Fed Induction Generator Applied to Wind Power Generator Technical Analyses
}

\author{
Deng-Chern Sue \\ Pacific Engineers \& Constructors, Ltd., Taipei, China \\ E-mail:dcsue@pecl.com.tw \\ Received December 3, 2010; revised January 30, 2011; accepted February 28, 2011
}

\begin{abstract}
High efficiency Double-Fed Induction Generator applies new power electronic technology, and utilizes vector control to fix the magnetic direction of the stator to the vertical axis. Adjusting the input current of rotor via an inverter can separately control the cross axis and vertical axis current of real power and reactive power of a generator. Traditionally, rotating speed affects frequency and the output is unstable. This study concentrates on high efficiency Double-Fed Induction Generators and Traditional Generators from mathematic model to derive and control the characteristics simulation and comparison than get an output of high efficiency Double-Fed Industrial Generators. This study utilizes the simulation software MATLAB/Simulink to simulate the response characteristics of vector control of a Double-Fed Industrial Generator. The operating and control functions are better than those of a traditional generator.
\end{abstract}

Keywords: Double-Fed Induction Generator, Cut-in Speed, Pushover Torque, Stall Regulator, Pitch Regulator, Inverter

\section{Introduction}

Taiwan is an island; with most of its energy imported. Because of the shortage of an indigenous energy supply in Taiwan, the international energy market has a strong effect on the local economy. Utilizing fossil fuels may cause global warming and temperature variation. The International Kyoto meeting requested to decrease the fossil fuel consumption and minimize the $\mathrm{CO}_{2}$ emission to control the global warming effect. Therefore, American and European countries are concentrating on the study of renewable sources of energy, such as wind power, solar energy, ocean tides, hydro power biomass, etc., wherein the wind has a significant possibility of producing electric power.

The Taiwanese Government has set up "Sources of renewable energy policy" to increase the clean energy consumption and promote the renewable sources of energy.

This stable incentive policy creates the renewable sources of energy from the surrounding environment. It supports relative industrial development and promotes the renewable sources of energy for all applications.

Wind comes from the effects of solar and earth rotation. It causes airflow with kinetic energy. It is called wind power. Humanity has utilized wind-powered de- vices, such as sailboats, wind-powered water wheels, windmills, etc. In the late nineteenth century, a windpowered machine was connected with a generator to produce power. Wind power becomes a main application for wind energy [1].

On Taiwan, the annual northeast monsoon produces strong winds along the coast, mountain and remote island areas. According to a recent investigation, over $2000 \mathrm{~km}^{2}$ of land area has an annual average wind speed higher than $5 \mathrm{~m} / \mathrm{s}$. Wind energy has an excellent potential and the minimum recoverable wind energy is estimated at around $1000 \mathrm{MW}$. Taiwan has abundant wind energy.

Currently, the Peng-Hu Chung Tun Power Station and Taiwan Formosa Plastic Mai-Liao Power Station have installed wind-powered generators, which have operated successfully. However, Taiwan has a limited experience and few studies have been made on wind power. This study concentrates on the analysis and comparison of output characteristics for high efficiency Double-Fed Induction Generator and Traditional Generator.

\section{Wind Power Efficiency}

Rotation of the earth and solar radiation induce tempera- 
ture differences at the earth's surface cause air circulation. Airflow in the horizontal direction produces wind. The wind velocity has the following units: $\mathrm{m} / \mathrm{s}, \mathrm{km} / \mathrm{hr}$, $\mathrm{mph}$ knots (nautical mile/hr), with the relationships as

$$
1 \mathrm{~m} / \mathrm{s}=3.6 \mathrm{~km} / \mathrm{hr}=2.24 \mathrm{mph}=1.94 \text { knots }
$$

In addition, the Beaufort scale can be used to identify the wind strength. The wind strength has 0 up to 17 grade (wind velocity from $0.3 \mathrm{~m} / \mathrm{s}$ to $61.2 \mathrm{~m} / \mathrm{s}$ ). Wind pressure $(\mathrm{F})$ is produced from airflow that is directly proportional to the cube (per formula) of its velocity.

$$
F=\frac{1}{2} C_{P} \rho A U^{2}(\mathrm{~kW})
$$

where

$A$ : cross-sectional area of wind stream $\left(\mathrm{m}^{2}\right)$

$\rho:$ air density $\left(1.225 \mathrm{~kg} / \mathrm{m}^{3}\right)$

$C_{P}$ : wind power coefficient

$U$ : wind velocity $(\mathrm{m} / \mathrm{s})$

The kinetic of wind pressure is called wind power $(P)$, which is wind pressure $(F)$ produced work per unit time,

$$
P=\frac{1}{2} C_{P} \rho A U^{3}
$$

For stall regulator, $C_{p}$ is a $\lambda$ function and $\lambda$ is a ratio of the velocity at wind tip of regulator vs. wind velocity, i.e. $\lambda=r \omega / V$ and $r$ is the rotor radius of wind machine, $\omega(\mathrm{rad} / \mathrm{s})$ is angle velocity, Figure $\mathbf{1}$ is the $C_{P}-\lambda$ curve of various angles.

The power produced by a wind machine is directly proportional to its cross-sectional area, and the cube of the wind's velocity [2-4]. Therefore, the wind machine's location is the key factor of power production and power generating cost.

The wind machine operating at a pre-set range of wind velocities has to ensure the generator operates at rated speed. Means must be provided to shutdown the generator operating to protect the equipment if the wind veloc-

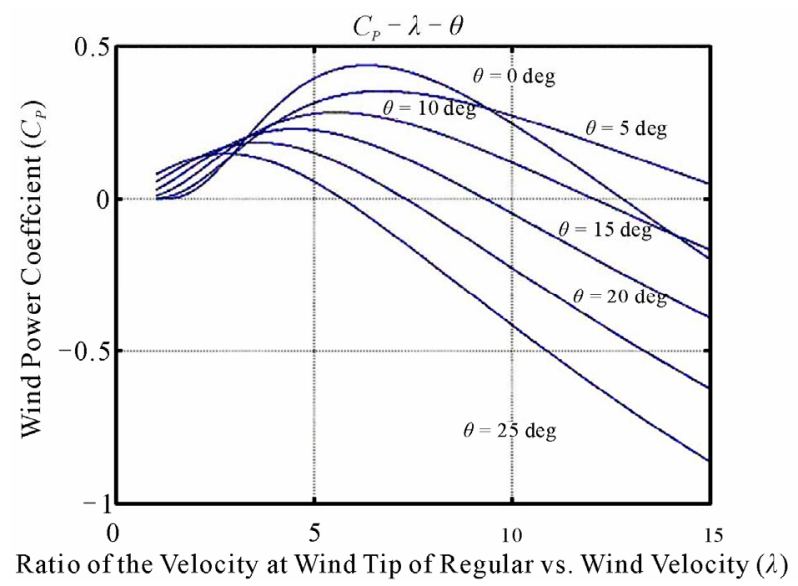

Figure 1. $C_{P}-\lambda$ curve of various angles. ity becomes excessive. But, the theoretical kinetic energy of the wind can only be partially utilized considering the overall efficiency of machine; only a part of wind power can be actually utilized.

\section{Characteristics of Wind Machine}

The kinetic energy of the moving air (wind) rotates the blades of the wind machine. The blades convert the wind energy to mechanical energy, which in turn, is converted to electrical energy by the generator. The power output of wind machine is affected by wind velocity, machine efficiency, blade design, blade pitch, cross-sectional area, etc. $[1,2]$.

The wind machines type can be categorized into horizontal shaft and vertical shaft depends on shape and rotating shaft. The vertical shaft machine has a higher axial retardation factor, lower rotating speed, lower efficiency and requires more blade material, making it unsuitable for power generating use. The horizontal shaft machine can be categorized as facing upwind or downwind. The upwind machine uses a rear rudder (small machine) or universal mechanism to sense the wind direction and position the blades to produce maximum power. The downwind type uses the cone shape to minimize of the rotor to follow wind direction so the blades are facing the downwind side. Because the wind acts on the supporting structure of the wind machine and then on the blades, the resulting periodic fatigue loadings affects the machine operating life. In general, horizontal shaft wind machines are the upwind type, i.e., blades are facing the wind. Figure 2 shows horizontal shaft wind machine type.

The blade selection significantly affects the rotating speed and power output of machine. Currently, the major blades type is three-blades type. The three-blades has less loading variation more stable operation, decreased fatigue loadings, increased blade operating life compared to two blade and single blade units. In additional, the

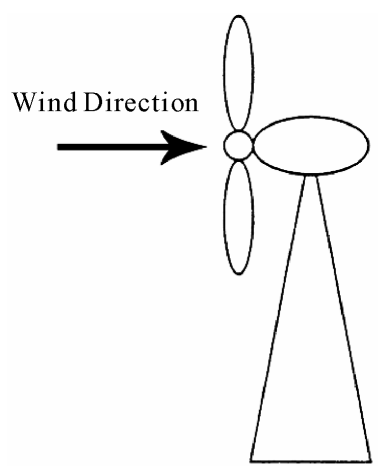

(a)

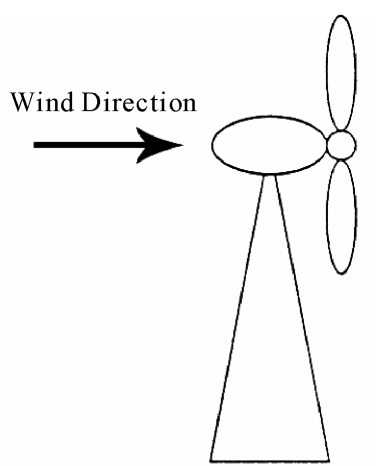

(b)
Figure 2. Horizontal shaft wind machine type. (a) Upwide; (b) Downwind. 
operation of three-blade is smooth and comfortable of vision, the two-blade units have an unstable rotation and single blade units are unbalance and uncomfortable. Therefore, the horizontal three-blades are selected for the current study of wind machines. Accordingly, the horizontal shaft, upwind and three-blade wind machines are evaluated as the best approach for an operating wind machine [1].

The power output is related to wind velocity or wind speed. When the wind speed matches the cut-in speed, the wind machine begins to produce power. From cut-in speed to the rated speed, the wind machine power output is directly proportional to the cube of the wind velocity. From the rated speed to cut-out speed, the power output remains at rated power. When the cut-out speed exceeded, the wind machine is shut down without power output to avoid any damage. The blades must be feathered to have no significant rotational velocity. Figure 3 shows wind velocity and power output of Vestas V47-660 Type Wind Power Generator at rated power $660 \mathrm{~kW}$, the cut-in speed, rated speed, and cut-out speed are 4,15 and $25 \mathrm{~m} / \mathrm{s}$ respectively.

To maintain the rated power output for wind machine and without damaging the gearbox and/or generator, the power output of the wind machine has to be controlled. Control is separated into a stall regulator and a pitch regulator to control the amount of wind energy being absorbed and transferred to produce power [1,2]. Table 1 is the comparison of stall regulator and pitch regulator.

\section{Traditional Wind Machine Output Characteristics}

Currently, the major types of wind-powered generators are permanent magnet generator, synchronous generator, induction generator, and high efficiency double-fed generator $[2,5]$. The theory and output characteristics of the different types of wind-powered generators are explained as follows:

\subsection{Permanent Magnet Generator}

The rotor of the generator is made of permanently magnetic material and the rotor shaft is driven by the blades of the unit. When the rotating blades drive the magnetic rotor, a rotating magnetic field that interacts with the multiple windings of the stator. These rotating lines of magnetic force induce an alternating voltage in the windings. The alternating current induction voltage is

$$
E_{A}=K \phi \omega
$$

where

$$
K \text { : electrical coefficient of the generator }
$$

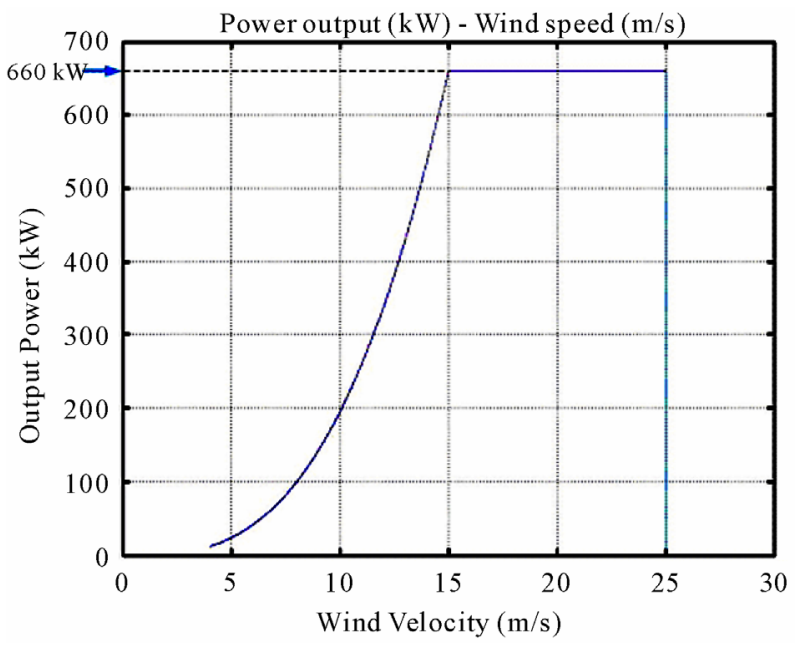

Figure 3. Wind velocity and power output of vestas V47-660 type wind power generator.

\begin{tabular}{|c|c|c|}
\hline Item & Stall Regulator & Pitch Regulator \\
\hline Output Characteristics & $\begin{array}{c}\text { Has small range of } \\
\text { output characteristic } \\
\text { curve }\end{array}$ & $\begin{array}{c}\text { Has large range of } \\
\text { output characteristics } \\
\text { curve }\end{array}$ \\
\hline $\begin{array}{c}\text { Constant Speed } \\
\text { Control }\end{array}$ & $\begin{array}{l}\text { Can meet control } \\
\text { requirements }\end{array}$ & $\begin{array}{c}\text { Has difficulty at high } \\
\text { wind speed }\end{array}$ \\
\hline $\begin{array}{c}\text { Variable Speed } \\
\text { Control }\end{array}$ & Can't meet & $\begin{array}{l}\text { Has better power } \\
\text { quality and lower } \\
\text { transmission load } \\
\text { compare to stall } \\
\text { regulator }\end{array}$ \\
\hline Start Wind Velocity & Higher wind velocity & Lower wind velocity \\
\hline Safety & $\begin{array}{l}\text { Needs breaker system } \\
\text { to protect over speed }\end{array}$ & $\begin{array}{c}\text { Without over speed } \\
\text { problem }\end{array}$ \\
\hline Structure & $\begin{array}{c}\text { Structure and } \\
\text { maintenance } \\
\text { are easier }\end{array}$ & $\begin{array}{c}\text { Structure and } \\
\text { maintenance more } \\
\text { complicated }\end{array}$ \\
\hline Cost & Lower cost & Higher cost \\
\hline
\end{tabular}

Table 1. Comparison of stall regulator and pitch regulator.

$\phi:$ rotor magnetic flux $(\mathrm{Wb})$

$\omega:$ angle velocity of rotor speed $(\mathrm{rad} / \mathrm{sec})$

Because the rotating magnetic field is fixed and the rotor rotating speed varies with wind velocity, the output voltage and frequency are variable and cannot provide a stable power supply. The produced power must be run through a rectifier and an inverter to be compatible with a $60 \mathrm{~Hz}$ power system. Due to the small capacity and higher cost per kilowatt of output, this type is not suitable for commercial applications. It is only suitable for remote areas without a grid power supply.

\subsection{Synchronous Generator}

A synchronous generator operates at the synchronous 
rotating speed of an alternating current system to which it is connected. A synchronous generator requires direct current to be supplied to the rotor winding via slipping to produce the rotor's magnetic flux. The prime mover (wind) drives the generator rotor forming a rotating magnetic field that induces a voltage in the stator windings of the unit. The windings of the stator are arranged so that a three-phase voltage is produced. Interactions of rotating magnetic field of synchronize rotation, which inducts a three-blades voltage. The induction voltage of alternating current is

$$
E_{A}=K \phi \omega_{s y n}
$$

where

$K$ : electrical coefficiency of generator

$\phi$ : rotor magnetic flux $(\mathrm{Wb})$

$\omega_{\text {syn }}$ : angular velocity of rotor rotating at synchronous speed

$\omega_{\text {syn }}=2 \pi f \quad(\mathrm{rad} / \mathrm{sec})$

$f$ : stator frequency, $f=n_{m} P / 120$

$n_{m}:$ rotor synchronize speed (rpm)

$P$ : number of rotor poles

Output power (neglecting stator resistance) is

$$
P_{\text {out }}=\frac{3 V_{T} E_{A}}{X_{s}} \sin \delta
$$

where,

$V_{T}$ : voltage across generator terminals (volts)

$X_{s}$ : synchronous reactance $(\Omega)$

$\delta$ : phase angle difference between $E_{A}$ and $V_{T}$ (degree).

In general, the large power supply system needs to use two sets or more synchronous generators to combine into system for supply power. It has the advantages of increased system efficiency, decreased spare capacity, ease of unit maintenance, increased power supply reliability and meeting optimal dispatch, etc. Figure 4 shows output power and torque angle for raised pole and cylindrical rotor of synchronous generator.

Synchronous generator applies to wind-powered units when the rotating blades directly drive the rotor without any gearbox, avoiding the noise and wear of meshing drive gears. When the actual wind speed exceeds the design wind speed and the unit is operating at full load, a pitch control system is installed to adjust the blade angle to reduce the power extracted from the wind. Pitch control limits rotor speed and power output to eliminate overload/overspeed damage.

The synchronous generator is same as the permanent magnet generator. The output voltage and frequency varies with the wind velocity. The wind machine normally rotates at $20-30 \mathrm{rpm}$ compared to the maximum synchronous speed of $3600 \mathrm{rpm}$ for a $60 \mathrm{~Hz}$ grid system.

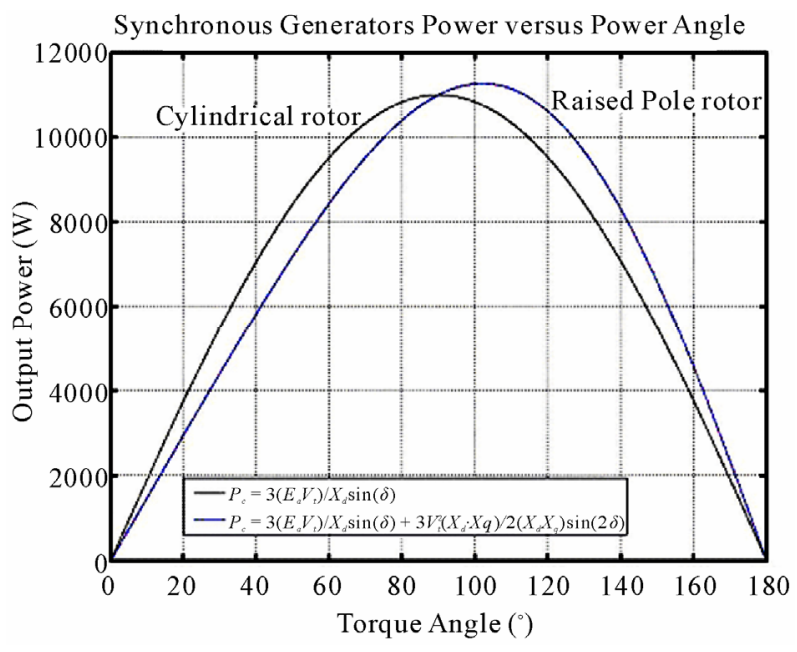

Figure 4. Output power characteristics of synchronous generator.

In order to make the wind machine's output compatible with the $60 \mathrm{~Hz}$ grid, the machine's output must pass through a rectifier to become a DC and then through an inverter to match the system frequency before being stepped-up via a transformer to feed into the power grid.

\subsection{Induction Generator}

The three-phase induction generator uses magnetic induction theory to transfer the electrical energy in the form of magnetic flux from stator to rotor, without any wire connection. Power from an external source energizes the stator, causing the rotor to turn, just like an induction motor. The rotating speed of the rotor is slightly lower than the rotating magnetic flux in the stator. This type generator is also called an asynchronous machine. When the rotor speed of an induction generator exceeds the speed rotating magnetic field in the stator, and the rotor direction is consistent with rotating magnetic field, the rotor will tend to pull the stator field faster. This action causes a reverse torque in the rotating direction, thus causing the induction generator to operate as a generator at the frequency and voltage of the initial power supply to the stator. In a properly designed machine, the magnetic link between the rotor and stator is strong enough to prevent the rotor going into over speed, regardless of the energy input from the blades. The definition of rotating difference ratio for an induction generator is

$$
s=\frac{n_{s y n}-n_{m}}{n_{\text {syn }}} \times 100 \%
$$

where,

$$
n_{\text {syn }}: \text { synchronous speed of magnetic field (rpm) }
$$$$
n_{m}: \text { rotor speed of rotor }(\mathrm{rpm})
$$ 
Figure 5 follows Kirchhoff's voltage law, the voltage loop equation for single-phase effective circuit of an induction generator is

$$
\begin{gathered}
V_{s}=\left[R_{s}+j\left(X_{s}+X_{m}\right)\right] I_{s}+j X_{m} I_{r} \\
0=j X_{m} I_{s}+\left\langle\frac{R_{r}}{s}+j\left[X_{r}+X_{m}\right]\right\rangle I_{r}
\end{gathered}
$$

In Equations (7) and (8), only the magnetic reactance, $j X_{m}$, is considered and the flux branch resistance of the core, $R_{c}$, is neglected. The conversion power and torque of an induction generator are represented as

$$
\begin{gathered}
P_{\text {conv }}=3 I_{r}^{2} R_{r}\left(\frac{1-s}{s}\right) \\
\tau_{\text {ind }}=\frac{P_{\text {conv }}}{\omega_{m}}
\end{gathered}
$$

Figure 6 shows the torque-speed characteristics curves of induction generators with differing rotor resistance values. The produced power is directly proportional to the torque applied to the stator by the blades and thus rotor, but if the input torque developed by the wind on the blades, is larger than pushover torque, the induction

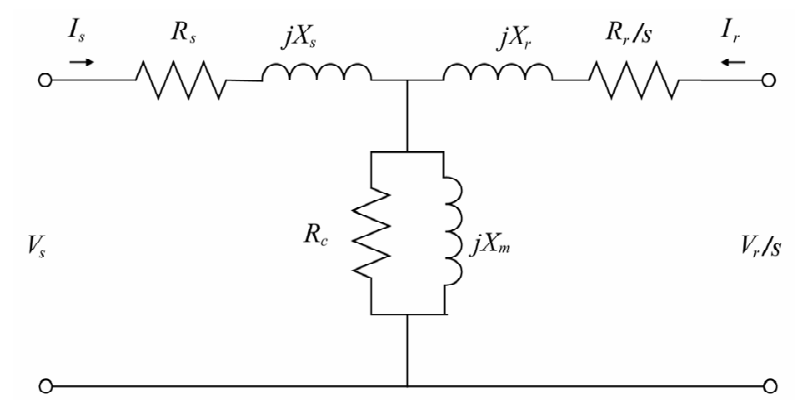

Figure 5. Effective circuit of a single phase of an induction generator.

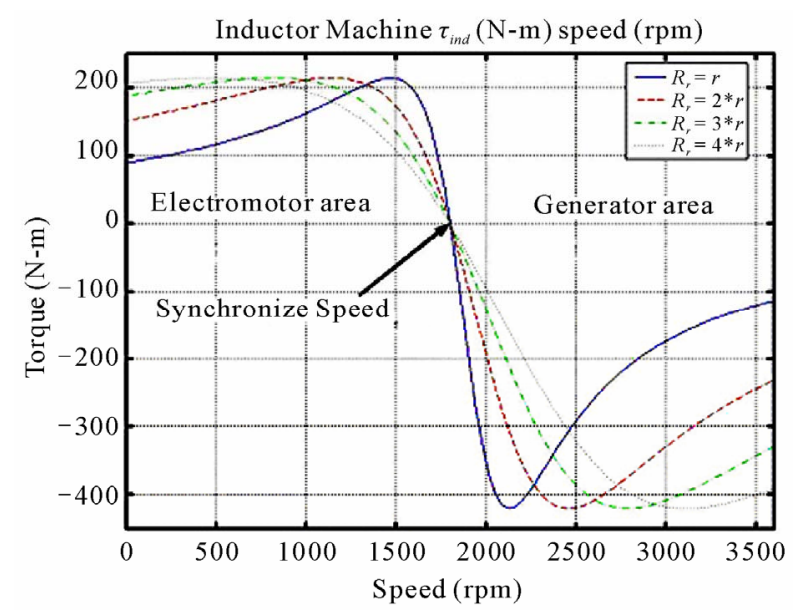

Figure 6. Torque-speed characteristic curve of an induction generator with different rotor resistance values. generator will over speed. Therefore, when applied to a wind-powered generator an adequate breaker, rotor resistance control, blade pitch control or similar devices to prevent high wind speed and/or excessive torque from inducing over speed of the blades and rotor [1].

The induction generator rotor is without a magnetic field circuit, to change the magnetic field to control the output voltage and is not self-exciting. The required reactive power for excitation needs is supplied by a connection from an external capacitor or from grid system. The excitation power controls the voltage at the generator terminals, which supply the power to grid system [5]. The advantages of induction generator are structural simplification; exciting field system is not required, unnecessary to synchronize operation, easy for operation and maintenance. When induction generator derives power from wind, the self-exciting type is used. A capacitor is installed across the terminals to provide the required reactive power for startup and improve the power factor during operation.

\subsection{Comparison Synchronous Generator and Induction Generator}

The stator construction is identical for a synchronous generator and an induction generator. The major difference is rotor design and construction. The winding of rotor of a synchronous generator need to have direct current (DC) for excitation to produce the rotor's magnetic field but the damper windings of the rotor of the induction generator need to be short-circuited to produce rotor magnetic field. Table 2 shows the comparison of syn-

\begin{tabular}{|c|c|c|}
\hline Items & Synchronous Generator & Induction Generator \\
\hline Stator structure & Three-phase winding & $\begin{array}{l}\text { Three-phase } \\
\text { winding }\end{array}$ \\
\hline Rotor structure & $\begin{array}{l}\text { Has evidenced and } \\
\text { controlled pole rotor } \\
\text { winding need to } \\
\text { connect to DC source }\end{array}$ & $\begin{array}{c}\text { Has cage rotor, winding } \\
\text { doesn't need to connect } \\
\text { DC }\end{array}$ \\
\hline Speed & $\begin{array}{c}\text { Operating at } \\
\text { synchronize speed }\end{array}$ & $\begin{array}{c}\text { Operating at } \\
\text { over-synchronous speed }\end{array}$ \\
\hline $\begin{array}{l}\text { Reactive power } \\
\text { compensation }\end{array}$ & Not needed & $\begin{array}{l}\text { From system or } \\
\text { connect to capacitor }\end{array}$ \\
\hline $\begin{array}{l}\text { End voltage } \\
\text { control }\end{array}$ & $\begin{array}{l}\text { Cause exciting system } \\
\text { control }\end{array}$ & Can't control \\
\hline Converter device & Needed & Not needed \\
\hline Maintenance & Complicate and difficult & Simple and easy \\
\hline Cost & Expensive & Cheap \\
\hline
\end{tabular}
chronous and induction generators.

Table 2. Performance comparisons of synchronous and induction generators. 


\section{High Efficiency Double-Fed Induction Generator}

The disadvantages and limitations of the self-exciting induction generator include the difficulty to adjust the output voltage and frequency, the need to be operated at over-synchronous speed, the small range of output power, etc. Currently, new developments in the windings of the induction generator and vector control theory as applied to controlling the rotor input voltage and frequency can modulate the power input and output characteristics of the generator rotor. With the advantages of operating in an aubsynchronous speed range, output can exceed rated power; closer control of output voltage and frequency is obtained. Figure 7 shows a double-fed induction generator structure [2].

\subsection{Model of Double-Fed Induction Generator}

After transformation and d-q transformation of a threephase dynamic model for a double-fed induction generator $[3,4]$, the equations of dynamic model can be written as:

$$
\begin{gathered}
V_{d s}=R_{s} I_{d s}+\frac{\mathrm{d} \psi_{d s}}{\mathrm{~d} t}-\omega_{s} \psi_{q s} \\
V_{q s}=R_{s} I_{q s}+\frac{\mathrm{d} \psi_{q s}}{\mathrm{~d} t}+\omega_{s} \psi_{d s} \\
V_{d r}=R_{r} I_{d r}+\frac{\mathrm{d} \psi_{d r}}{\mathrm{~d} t}-\omega_{r} \psi_{q r} \\
V_{q r}=R_{r} I_{q r}+\frac{\mathrm{d} \psi_{q r}}{\mathrm{~d} t}+\omega_{r} \psi_{d r} \\
\tau_{m}=\tau_{e}+J \frac{\mathrm{d} \omega_{r}}{\mathrm{~d} t}+f \omega_{r} \\
\tau_{e}=\frac{M}{L_{s}}\left(\psi_{q s} I_{d r}-\psi_{d s} I_{q r}\right)
\end{gathered}
$$

where

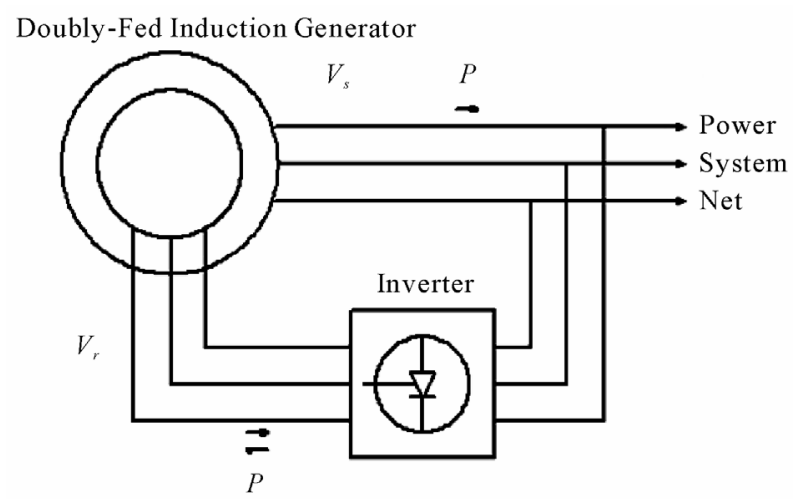

Figure 7. Structure of double-fed induction generator.

$$
\begin{gathered}
\omega_{r}: \text { angle speed of rotor }\left(\omega_{r}=s \omega_{s}, \mathrm{rad} / \mathrm{sec}\right) \\
\psi_{d s}=L_{s} I_{d s}+M I_{d r} \\
\psi_{q s}=L_{s} I_{q s}+M I_{q r} \\
\psi_{d r}=M I_{d s}+L_{r} I_{d r} \\
\psi_{q r}=M I_{q s}+L_{r} I_{q r}
\end{gathered}
$$

Due to generator operating at steady condition, therefore, with further analysis, the term $\frac{\mathrm{d} \psi}{\mathrm{d} t}$ can be neglected, allowing the voltage of stator and rotor to be re-written as:

$$
\begin{aligned}
& V_{d s}=R_{s} I_{d s}-\omega_{s}\left(L_{s} I_{q s}+M I_{q r}\right) \\
& V_{q s}=R_{s} I_{q s}+\omega_{s}\left(L_{s} I_{d s}+M I_{d r}\right) \\
& V_{d r}=R_{r} I_{d r}-\omega_{r}\left(L_{r} I_{q r}+M I_{q s}\right) \\
& V_{q r}=R_{r} I_{q r}+\omega_{r}\left(L_{r} I_{d r}+M I_{d s}\right)
\end{aligned}
$$

\subsection{Related Equations of Vector Control}

The output of double-fed induction generator is connected to power system; therefore, the voltage of shaft end is equal to the voltage of system. The vector control theory is to fix magnetic direction of stator to the vertical axis.

$$
\begin{aligned}
& \psi_{d s}=\psi \text { and } \omega_{q s}=0 \\
& \tau_{e}=-\frac{M}{L_{s}} \psi_{d s} I_{q r}
\end{aligned}
$$

The magnetic torque is only related with rotor current of cross-axis. Neglect wire resistance of stator, $R_{\mathrm{s}}$ the voltage of stator end and voltage of vertical axis-cross axis for double-fed induction generator can be written as:

$$
\begin{aligned}
& V_{s n} \cong \frac{\mathrm{d} \psi_{s n}}{\mathrm{~d} t} ; n=a, b, c \\
& V_{d s}=0 \text { and } V_{q s}=V_{s}
\end{aligned}
$$

Use vertical axis-cross axis as reference base, rewrite the voltage, current and magnetic of stator end, as follow:

$$
\begin{gathered}
V_{d s}=0 \\
V_{q s}=V_{s}=\omega_{s} \psi_{d s} \\
\psi_{d s}=L_{s} I_{d s}+M I_{d r}=\psi_{s} \\
\psi_{q s}=L_{s} I_{q s}+M I_{q r}=0 \\
\psi_{d r}=M I_{d s}+L_{r} I_{d r} \\
\psi_{q r}=M I_{q s}+L_{r} I_{q r} \\
I_{d s}=\frac{1}{L_{s}}\left(\psi_{s}-M I_{d r}\right) \\
I_{q s}=-\frac{M}{L} I_{q r}
\end{gathered}
$$


Derivative from the above equation, the magnetic field and voltage of rotor is

$$
\begin{gathered}
\psi_{d r}=\left[L_{r}-\frac{M^{2}}{L_{s}}\right] I_{d r}+\frac{M V_{s}}{\omega_{s} L_{s}} \\
\psi_{q r}=\left[L_{r}-\frac{M^{2}}{L_{s}}\right] I_{q r} \\
V_{d r}=R_{r} I_{d r}+\left[L_{r}-\frac{M^{2}}{L_{s}}\right] \frac{\mathrm{d} I_{d r}}{\mathrm{~d} t}-s \omega_{s}\left[L_{r}-\frac{M^{2}}{L_{s}}\right] I_{q r} \\
V_{q r}=R_{r} I_{q r}+\left[L_{r}-\frac{M^{2}}{L_{s}}\right] \frac{\mathrm{d} I_{q r}}{\mathrm{~d} t}+s \omega_{s}\left[L_{r}-\frac{M^{2}}{L_{s}}\right] I_{d r} \\
+s \omega_{s} \frac{M V_{s}}{\omega_{s} L_{s}}
\end{gathered}
$$

The real power and reactive power of the stator of a double-fed induction generator can be presented as:
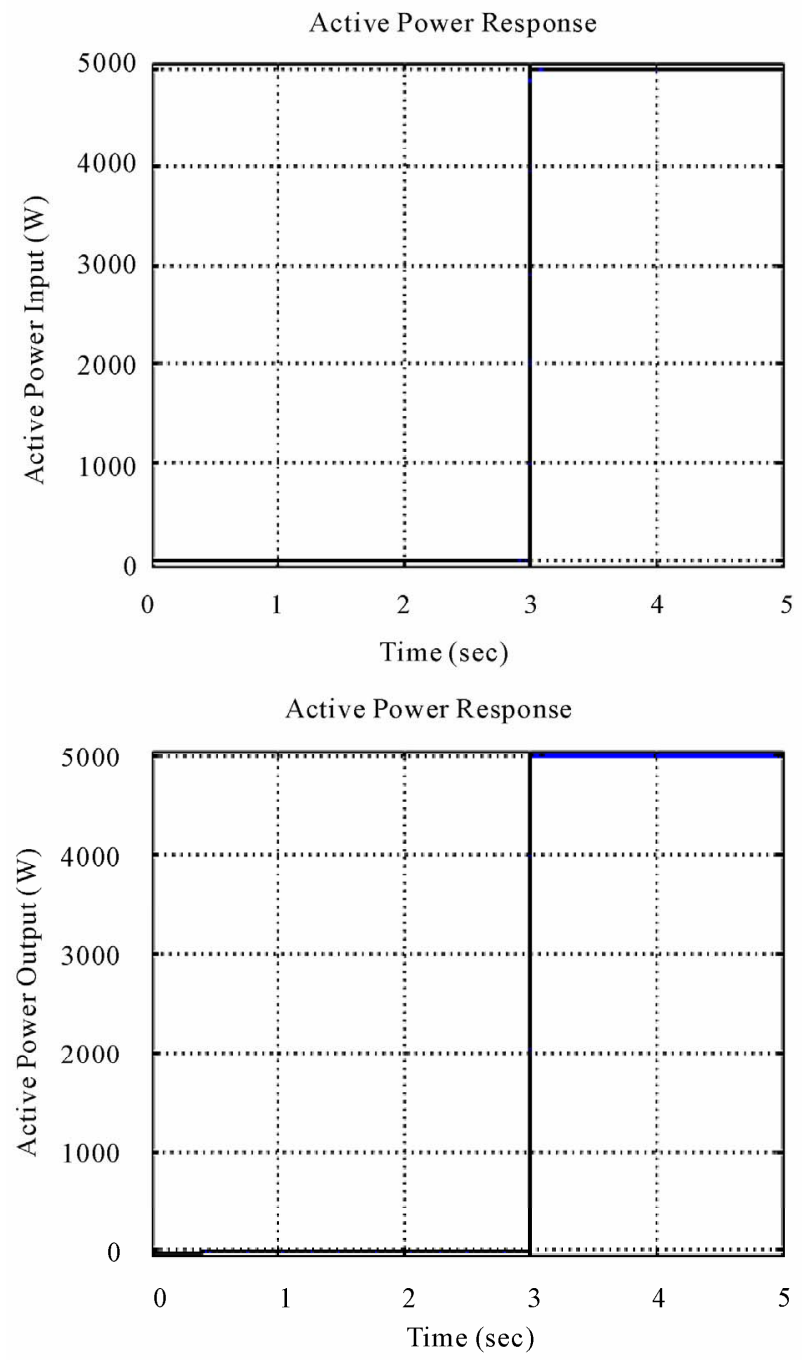

$$
\begin{aligned}
& P_{s}=V_{d s} I_{d s}+V_{q s} I_{q s}=-\frac{V_{s} M}{L_{s}} I_{q r} \\
& Q_{s}=V_{q s} I_{d s}-V_{d s} I_{q s}=\frac{V_{s} \psi_{s}}{L_{s}}-\frac{V_{s} M}{L_{s}} I_{d r}
\end{aligned}
$$

From the above derivative, the real power and reactive power of stator for the double-fed induction generator can be calculated. The current of vertical axis and cross axis for rotor can be separately controlled.

\subsection{Simulation Analysis}

If the software MATLAB/Simulink is used to simulate the vector control response characteristic of Double-Fed Induction Generator, and the above theoretical derivative is solved using the following simulation parameters with the results shown on Figures 8 and 9:
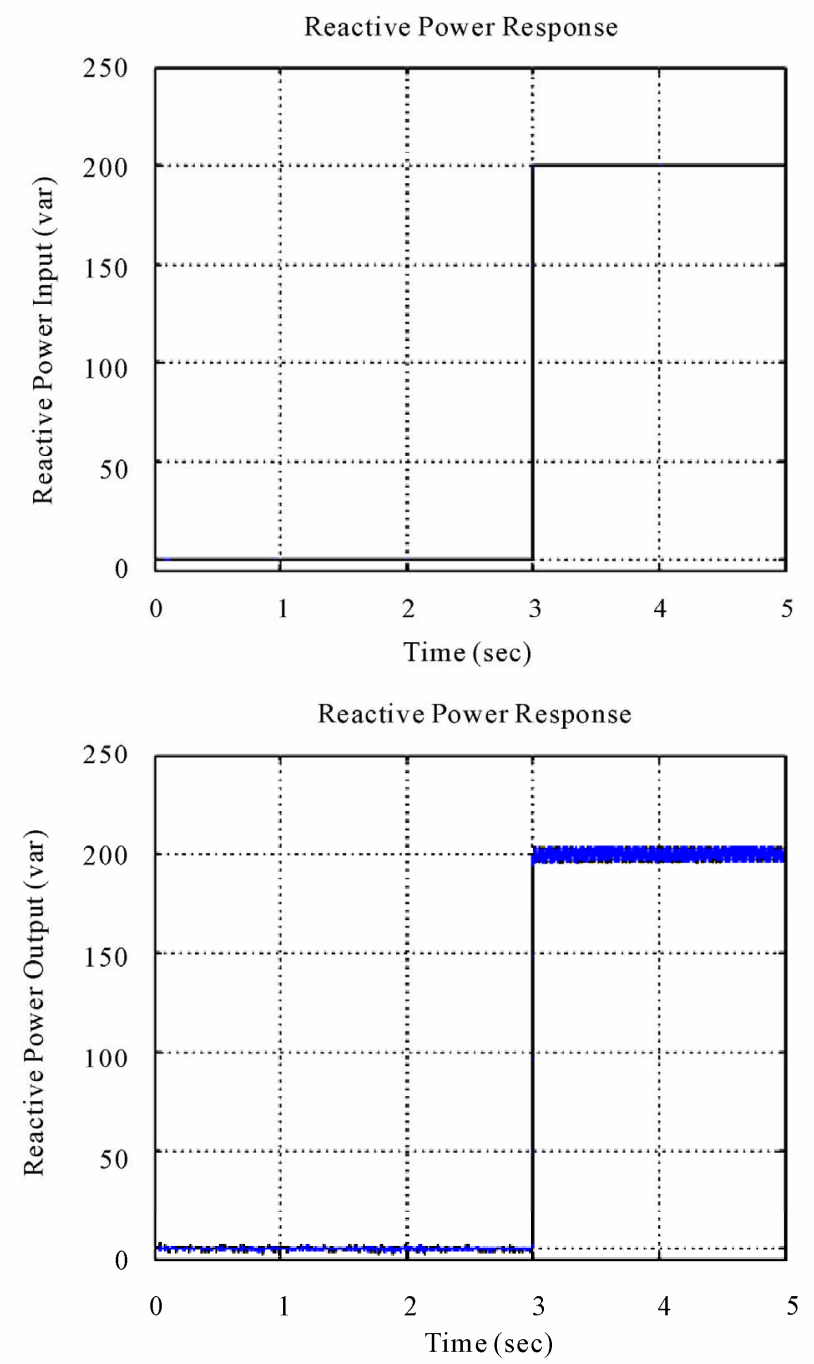

Figure 8. Simulation of response results for real power and reactive power. 

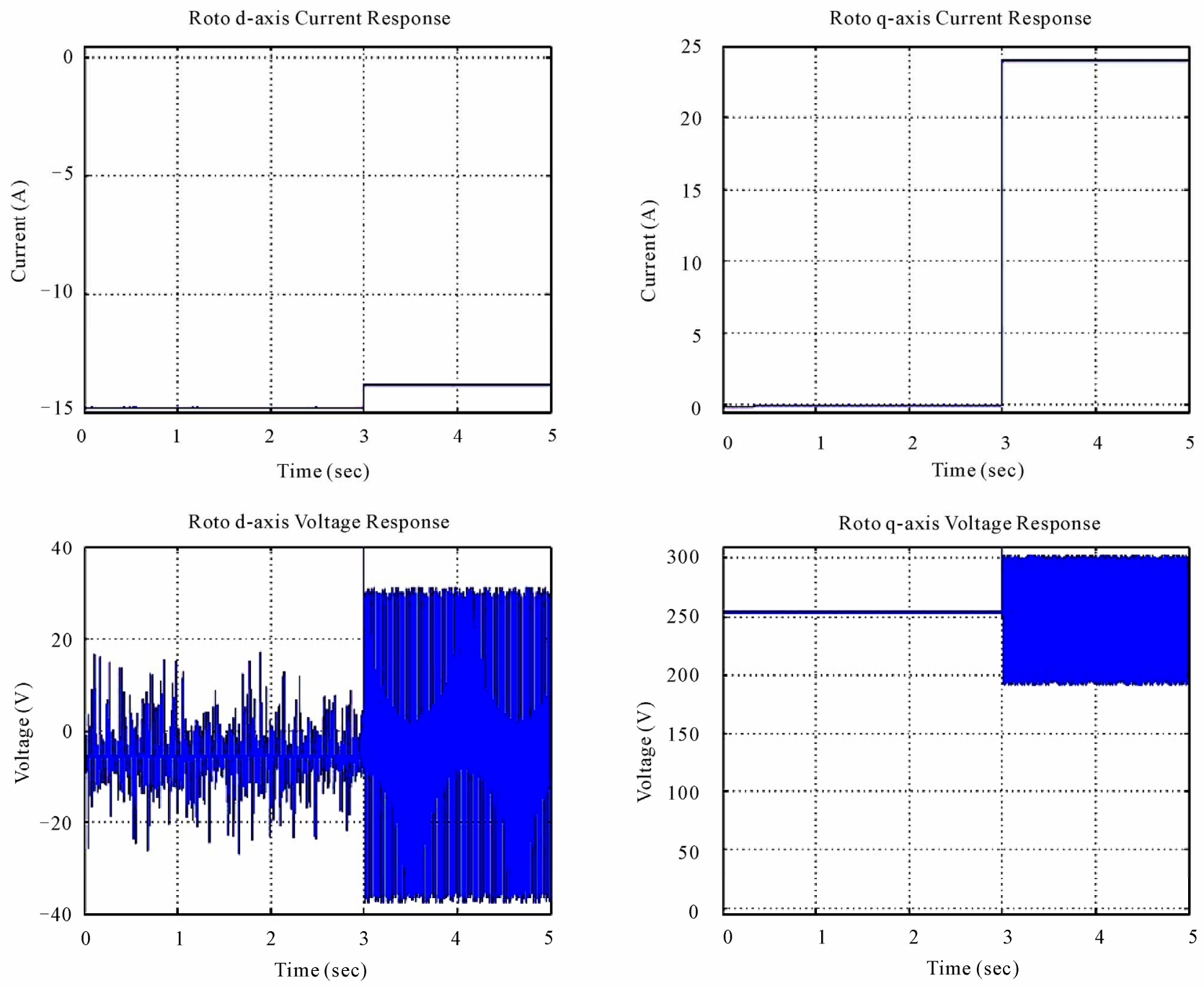

Figure 9. Simulation of response results of control current for rotor's vertical axis and cross axis.

$$
\begin{gathered}
R_{s}=0.05 \Omega, R_{r}=0.05 \Omega, M=47.3 \mathrm{mH}, \\
L_{s}=50 \mathrm{mH}, \quad L_{r}=50 \mathrm{mH}
\end{gathered}
$$

The generator power output is $5000 \mathrm{~W}$ and speed is $3600 \mathrm{rpm}$. The power control setting of Double-Fed Induction Generator is $5000 \mathrm{~W}$ for real power and 200 VAR for reactive power, speed is $3420 \mathrm{rpm}(s=0.05)$.

From the above simulation results, the vector control of a high efficiency Double-Fed Induction Generator and the magnetic field of the stator is fixed on the vertical axis. The real power and reactive power components of the output only related to the relative strengths of the current of cross axis and the vertical axis of the rotor. The generator can operate at lower than synchronous speed, which does not limit to operate at over the synchronous speed. At over synchronous speeds, the stator and rotor produce power; therefore, the output is higher than the rated power and has an excellent characteristic of voltage and frequency adjustment.

\section{Conclusions}

From the above analysis and because suitable wind power is available in Taiwan, the following conclusions are derived:

1) Use the vector control for the high efficiency Double-Fed Induction Generator, to control the output power of the wind-powered generator. Even if the wind velocity is unstable, it can rapidly adjust the current in the cross axis and vertical axis of the rotor to control the ratio of real power to reactive power to obtain the desired characteristics of the output power.

2) The generator can be operated sub-synchronous speeds and output is higher than the rated power. It has excellent adjustment characteristics for voltage and frequency. Therefore, the high efficiency Double-Fed In- 
duction Generator is an optimal selection for new windpowered generator applications.

\section{References}

[1] T. Burton, D. Sharpe, N. Jenkins and E. Bossanyi, "Wind Energy Handbook," John Wiley \& Sons, Inc., Hoboken, 2001. doi:10.1002/0470846062

[2] A. Petersson, "Analysis, Modeling and Control of Double-Fed Induction Generator," $\mathrm{PhD}$ Thesis, Chalmers University of Technology, Gothenburg, 2003.
[3] L. Zhang and C. Watthanasarn, "A Matrix Converter Excited Double-Fed Induction Machine as a Wind Power Generator," 7th International Conference on Power Electronics and Variable Speed Drives, London, 21-23 September 1998, pp. 532-537. doi:10.1049/cp:19980583

[4] J. G. Slootweg, H. Polinder and W. L. Kling, "Dynamic Modelling of a Wind Turbine with Double Fed Induction Generator," Power Engineering Society Summer Meeting, Vancouver, 2011, pp. 644-649. doi:10.1109/PESS.2001.970114

[5] P. Kundur, "Power System Stability and Control," McGraw-Hill, Inc., New York, 1994. 